\title{
Comunidade Quilombola de Felipe: estudos em Product-Service Systems para incentivar a economia local
}

\author{
Felipe's Quilombola Community: Studies in Product-Service Systems to Encourage the \\ Local Economy
}

MOURÃO, Nadja Maria; Mestre; Universidade do Estado de Minas Gerais nadjamourao@gmail.com

MARTINS, Ivy Francielle Higino; Mestre; Universidade do Estado de Minas Gerais ivyhigino@gmail.com

MACIEL, Rosilene Conceição; Mestre; Universidade do Estado de Minas Gerais rmaciela@gmail.com

OLIVEIRA, Ana Célia Carneiro; Mestre; Universidade do Estado de Minas Gerais anaceliadesign@gmail.com

\section{Resumo}

Este artigo apresenta um processo metodológico de atuação do design realizado com base no PSS - Product Service Systems junto à comunidade quilombola de Felipe da cidade de Bom Jesus do Amparo em Minas Gerais. A equipe de designers foi contatada para estudar estratégias e iniciativas empreendedoras voltadas ao desenvolvimento local, à valorização da cultura e dos produtos do território. Como resultado, desenvolveu-se o projeto Sabores da Terra com o objetivo de promover um negócio local explorando os potenciais da comunidade. Propôs-se um serviço de buffet quilombola que tem como diretriz a difusão da cultura, o aproveitamento dos recursos locais e a valorização do território. O projeto valoriza o potencial da culinária afro-brasileira, presente na memória quilombola da comunidade de Felipe, aplicando o Aproveitamento Integral de Alimentos, e o design associado ao PSS como diferencial na implantação de atividades sustentáveis.

Palavras Chave: Product-Service Systems; quilombolas; economia local.

\begin{abstract}
This article presents a methodological process of design acting based on PSS - Product Service Systems to Felipes's quilombola community from Bom Jesus do Amparo city, Minas Gerais. The team of designers was hired to study strategies and entrepreneurial initiatives focused on local development, appreciation of the culture and of the products from the territory. As a result, the project Sabores da Terra was developed with the objective of promoting a local business exploring the community's potentials. A quilombola buffet service was proposed and has as guidelines spreading the culture, exploitation of local resources and territory appreciation. The project values the potential of afro-brazilian cuisine, present on the quilombola memory of the Community de Felipe, applying the Whole Food Usage, and the design associated to PSS as a differential when implanting sustainable activities.
\end{abstract}

Keywords: Product-Service Systems; quilombolas; local economy. 


\section{Introdução}

Na maioria dos países desenvolvidos, o setor de serviços tem uma participação de 70 a $80 \%$ de todo o produto interno bruto. Por isso, muitas empresas convencionais e de serviços comuns estão buscando compreender e integrar serviços sob a forma de Product-Service Systems (PSS), conforme Finken et al. (2013).

Os PSSs oferecem a possibilidade de diferenciação que não se restringe ao preço de produtos. Um PSS é uma estratégia focada no cliente, visando aumentar o valor através da compreensão pormenorizada das necessidades do cliente. Considera-se aqui a relevância da satisfação qualitativa do cliente, mais que a suficiência quantitativa dos produtos. Isso é alcançado, a partir de produtos valorizados pelo conteúdo do serviço e não apenas por questões técnicas ou materiais (COOK, 2004).

O Sustainable Product Service Systems (S.PSS) é um conceito distinto das ideias de produção limpa, design ecológico e design para o meio ambiente. O conceito ultrapassa a otimização ambiental de produtos e processos e requer um pensamento radical e criativo para reduzir os impactos ambientais, mantendo a qualidade do produto. Essa ecoeficiência é denominada de "fator 4", ou seja, uma melhoria em 4 vezes ou mais, que permite novas e radicais formas de transformar. É um "mix de serviço de produto" que satisfaz as demandas dos consumidores, além de melhorar os efeitos sobre o meio ambiente (ROY, 2000).

Os PSSs consideram Sociotechnical Systems (STS) alternativos que podem fornecer a função essencial de uso final, como o trabalho ou a mobilidade, que um produto existente produz ou oferece aos usuários. São delineados quatro tipos de serviços: serviços de resultados; serviços de utilização compartilhada de bens e produtos; serviços de extensão de vida útil de produtos; e gerenciamento de demanda compartilhada e distribuída de bens e produtos (HALEN; VEZZOLI; WIMMER, 2005).

Existem três incertezas principais quanto à aplicabilidade e viabilidade de um PSS: a prontidão das empresas para adotá-las, a prontidão dos consumidores para aceitá-las e suas implicações ambientais. Os PSSs bem-sucedidos exigirão infraestrutura social, estruturas humanas e layouts organizacionais para funcionar de maneira sustentável (COOK, 2004).

Roy (2000) esclarece que o sistema sociotécnico inclui pessoas e conhecimentos técnicos como partes inerentes ao sistema e necessárias à sua aplicação. Trata-se de uma abordagem de projeto organizacional complexo que reconhece a interação entre pessoas e tecnologia nos locais de trabalho e entre as complexas infraestruturas da sociedade e do comportamento humano.

A Secretaria Executiva do Território Metropolitano/Fóruns Regionais desenvolve atividades para contribuir com a comunidade Quilombola de Felipe na produção de alho e beneficiamento para tempero. A equipe de designers foi contatada para contribuir nas metas de desenvolvimento regional, em parceria com o centro acadêmico de design ${ }^{1}$. Nessa perspectiva, o trabalho desenvolvido pelos pesquisadores buscou o método de atuação do sistema sociotécnico, sob as bases do Sustainable Product Service Systems, para a comunidade quilombola de Felipe, do município de Bom Jesus do Amparo, em Minas Gerais.

\footnotetext{
${ }^{1}$ CEDTec - Centro de Estudos em Design e Tecnologia da Escola de Design - Universidade do Estado de Minas Gerais
} 
O objetivo inicialmente foi sistematizar a demanda da comunidade na forma de uma proposta para aplicação do PSS, de modo que a própria comunidade pudesse gerenciar o projeto. Embora seja necessária uma grande mudança nos hábitos e métodos de trabalho executados pela comunidade atualmente, acredita-se que a aplicação do PSS seja uma solução possível e promissora para o dilema do desenvolvimento sustentável de regiões economicamente desestruturadas.

\section{A Cidade de Bom Jesus do Amparo e a Comunidade de Felipe}

Localizada na Zona Metalúrgica do Estado de Minas Gerais (Brasil), a 76 km da cidade de Belo Horizonte, Bom Jesus do Amparo possui forte potencial para o turismo ecológico. Encontrase em território montanhoso com paisagens atraentes, em meio a riachos e cascatas. Há algumas pousadas rústicas entre as trilhas e, por estar próximo à capital, não necessita de muitas hospedarias. Porém, no momento, a prefeitura da cidade revela que as principais atividades econômicas da região são o agronegócio e a mineração. Essa é também uma preocupação, pois em breve não haverá minério suficiente para a exploração comercial. Nesse sentido, conforme informações da Prefeitura de Bom Jesus do Amparo (2017), é preciso projetar um novo futuro para a cidade.

A comunidade quilombola de Felipe está inserida no espaço urbano. É produtora festeira e religiosa (católicos e evangélicos), possui cerca de 700 remanescentes quilombolas. Recebeu o nome de "Felipe" em homenagem ao quilombo de mesmo nome que deu origem à comunidade. Na Figura 1, é apresentado um conjunto de fotografias capturadas na cidade de Bom Jesus do Amparo pela equipe do projeto.

Figura 1 - Imagens da cidade de Bom Jesus do Amparo.

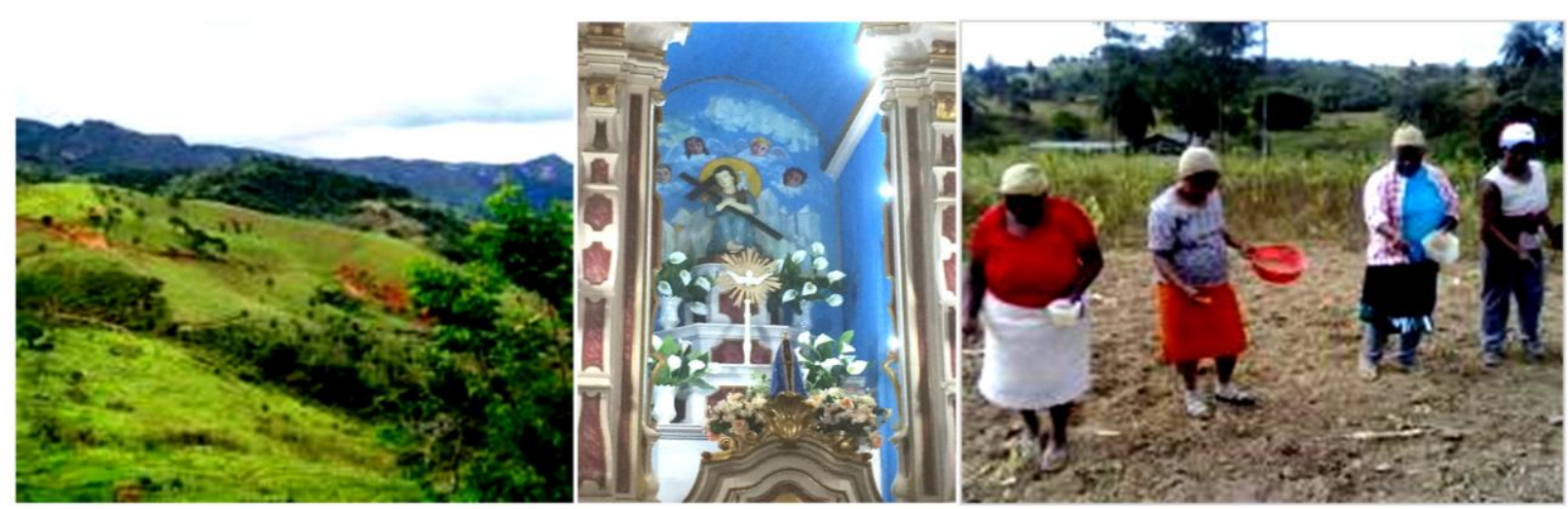

Fonte: Acervo do projeto (2017).

Apesar das qualidades humanas, territoriais e históricas da comunidade quilombola de Felipe, esta sofre com a falta de oportunidades de emprego e geração de renda. Uma das consequências desse problema é uma grande evasão de indivíduos ocorre nessa comunidade, principalmente, jovens em busca de oportunidades de estudo e trabalho.

Além disso, a falta de meios internos para a geração de renda levou muitas famílias a vender parte de suas terras para garantir seu sustento. Assim, Felipe vem passando por uma contínua fragmentação não apenas social, mas também territorial, que aponta para a necessidade de se investigar soluções de geração de renda e desenvolvimento autossustentável. 


\subsection{Demanda da Comunidade Quilombola de Felipe}

O Centro de Estudos em Design e Tecnologia (CEDTec) da Universidade do Estado de Minas Gerais recebeu um convite da Secretaria Executiva do Território Metropolitano/Fóruns Regionais, para contribuir com a comunidade Quilombola de Felipe. Além da produção de alho e tempero, há também um histórico cultural quilombola respeitado pelo poder público e pela comunidade.

Felipe demonstra ter potencial para a produção comercial de eventos e alimentos, pois, ao longo do ano, realiza várias comemorações comunitárias temáticas que incluem manifestações artísticas, produtos artesanais e comidas típicas produzidas por seus habitantes. Tais festividades, mesmo não sendo divulgadas de forma expressiva, atraem alguns visitantes que acabam se tornando pequenos e temporários consumidores de produtos locais. Na comunidade, há muitos artesãos que, dentre outros produtos, elaboram adornos a partir da palha de bananeiras (espécie em abundância no território). Outro ponto importante observado em Felipe é o desenvolvimento espontâneo e intuitivo de um sistema de produção sustentável tanto agrícola quanto de alimentos e produtos artesanais. A culinária tradicional dos quilombolas, por exemplo, frequentemente, realiza o aproveitamento integral dos alimentos, pois utiliza partes dos ingredientes orgânicos, que costumam ser descartas como resíduos inúteis, para produzir receitas típicas.

Acredita-se que esses fatores, trabalhados de uma forma menos intuitiva e mais projetual, podem contribuir para a promoção de uma geração de renda local significativa que ajude a solucionar os problemas econômicos desse grupo social. Voltada para esse propósito, a equipe de pesquisadores e designers do Centro Acadêmico (parceiro do projeto) executou um levantamento de dados sobre essa comunidade e identificou problemas a serem solucionados, tais como:

- A comunidade quilombola de Felipe não possui nenhuma marca identificadora para si ou para seus produtos, embora haja uma consciência de sua origem e identidade.

- O tempero de alho produzido pela comunidade não possui envasamento e rotulagem adequados para proteger, conservar e identificar o produto. A comunicação visual da embalagem também não explora fatores importantes que podem gerar valor para o produto, tais como sua forma de produção agroecológica e artesanal realizada por uma comunidade tradicional.

- Demanda de adequação da promoção de eventos e do processo de produção artesanal local para gerar renda e envolvimento dos membros da comunidade.

- Necessidade de orientação sobre o uso e a produção de embalagens naturais feitas a partir de cascas e palhas encontradas em abundância na comunidade. Essa possibilidade foi identificada pela observação de que a maioria dos produtos comercializados por Felipe possui um curto prazo para o consumo. Portanto, dispensam embalagens que os preservem por longos períodos. 


\section{PSS e os Novos Caminhos para a Comunidade de Felipe}

Manzini (2008, p. 26), esclarece que "para ser sustentável, um sistema de produção, uso e consumo tem que ir ao encontro das demandas da sociedade por produtos e serviços sem perturbar os ciclos naturais e sem empobrecer o capital natural". Nesse sentido, a equipe de designers buscou organizar a comunidade em um sistema de Arranjo Produtivo Local - APL e aprimorar sua produção por meio do desenvolvimento de um processo metodológico de atuação do design com base no PSS - Product Service Systems.

A equipe selecionou e aplicou ao projeto quatro ferramentas PSS: Persona, Empathy Map, Blueprint e System Map.

- Persona: as informações dos mapas de empatia foram utilizadas para a construção dos quatro principais perfis de persona envolvidos no projeto: um adulto da comunidade, um jovem da comunidade, um turista (Figura 2) e um representante da EMATER-MG, uma empresa de incentivo que oferece assistência técnica e extensão rural para comunidades tradicionais em parceria com os setores: público e privado.

Figura 2 - Exemplo resumido de persona construída: visitante ou turista potencial.

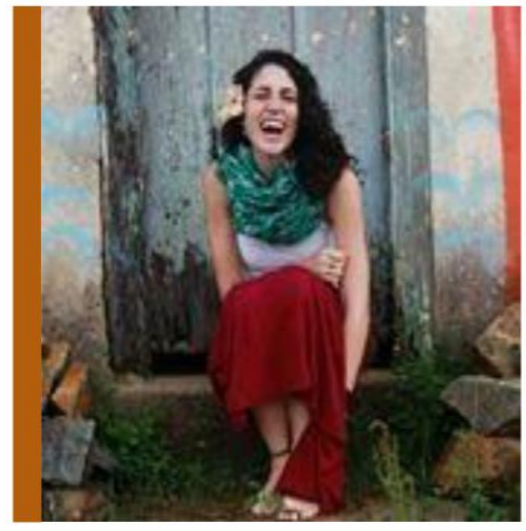

\section{3a PERSONA: VISITANTE/TURISTA}

\section{Isabela Marinho \\ 25 anos | Ensino superior em andamento \\ Pessoa interessada em turismo, culturas populares, tradições, gastronomia alternativa $e$ artesanato. Não conhece a comunidade de Felipe, mas é um cliente em potencial.}

Fonte: Elaborado pela equipe do projeto (2017).

- Mapa de Empatia (Empathy Map): foi utilizado para entender o problema envolvido no sistema produto/serviço de Felipe. Ele recebe o nome de "empatia" porque orienta na percepção do problema com profundidade. Devido a esse caráter humano, o mapa também foi útil para a compreensão das personas envolvidas nesse projeto. Por meio dessa ferramenta, a equipe listou o que cada persona pensa, sente, vê, fala, faz e ouve, conforme exemplifica a Figura 3. 
Figura 3 - Exemplo de mapa de empatia construído: visitante ou turista potencial.

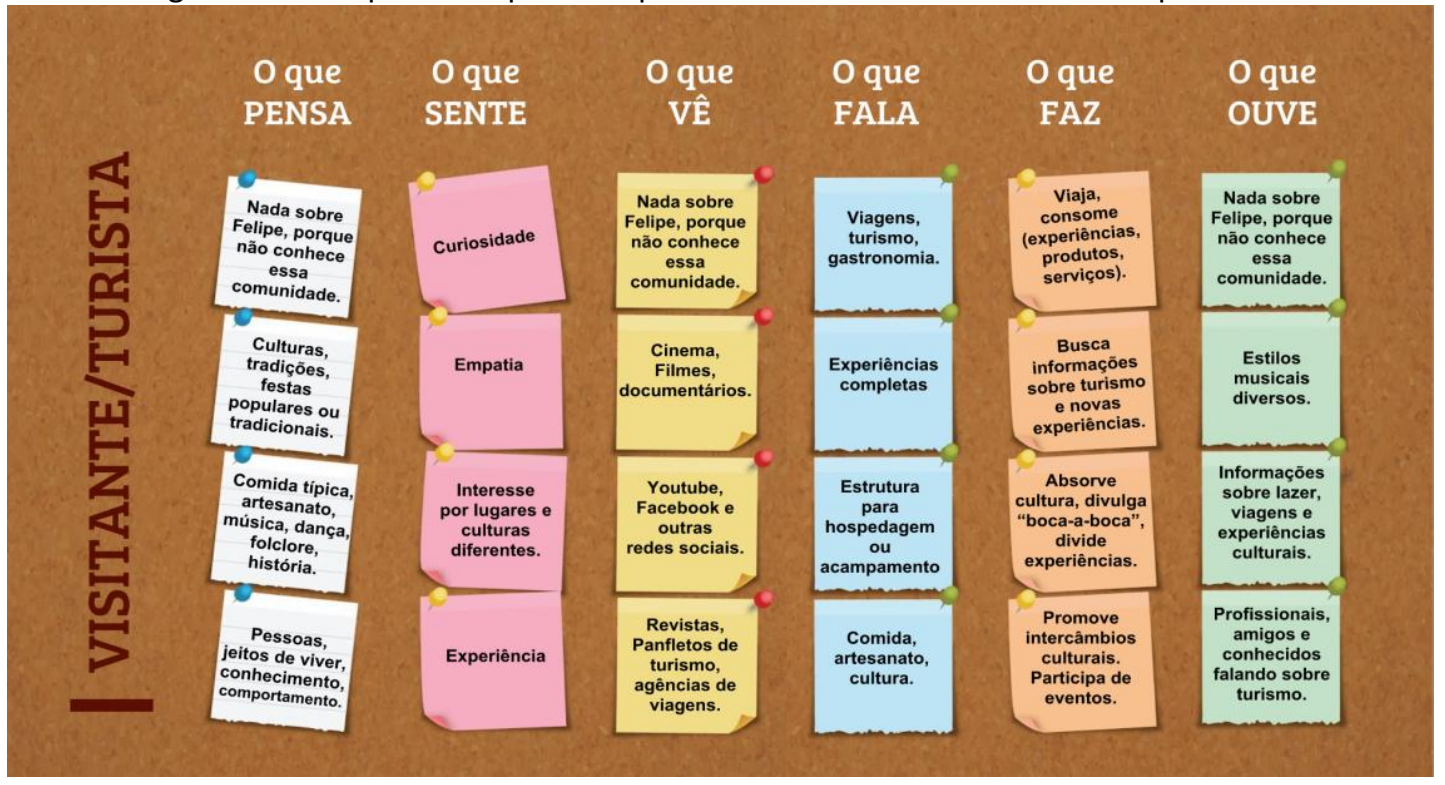

Fonte: Elaborado pela equipe do projeto (2017).

- Blueprint: a produção atual da Comunidade Quilombola de Felipe inclui o alho in natura, a pasta de alho, artesanatos diversos, quitandas (doces, bolos, biscoitos, compotas e outros) e comidas típicas. A ferramenta BluePrint foi utilizada para mapear o processo de serviço da comunidade, gerando um mapa para auxiliar no processo de desenvolvimento do PSS, conforme mostra a Figura 4.

Figura 4 - Mapa construído por meio do uso da ferramenta Blueprint.

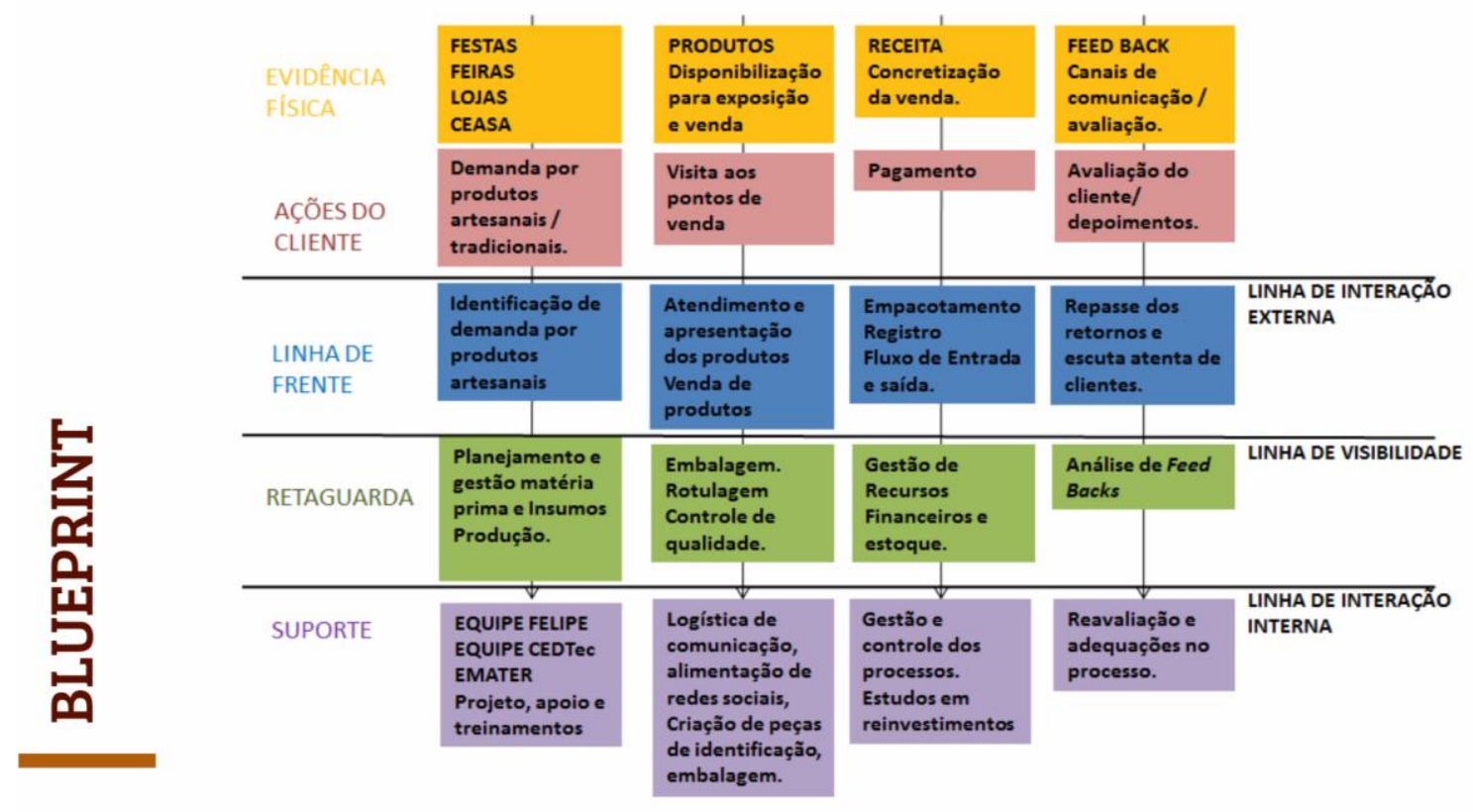

Fonte: Elaborado pela equipe do projeto, (2017). 
- System Map: esta ferramenta foi utilizada para a descrição visual da organização técnica do serviço. Nela a equipe destacou os diferentes atores envolvidos no sistema de produto/serviço de Felipe, suas ações e os fluxos de bens materiais, informações e de dinheiro. Essa descrição visual gerou o mapa apresentado na Figura 5.

Figura 5 - Mapa criado por meio do uso da ferramenta System Map.

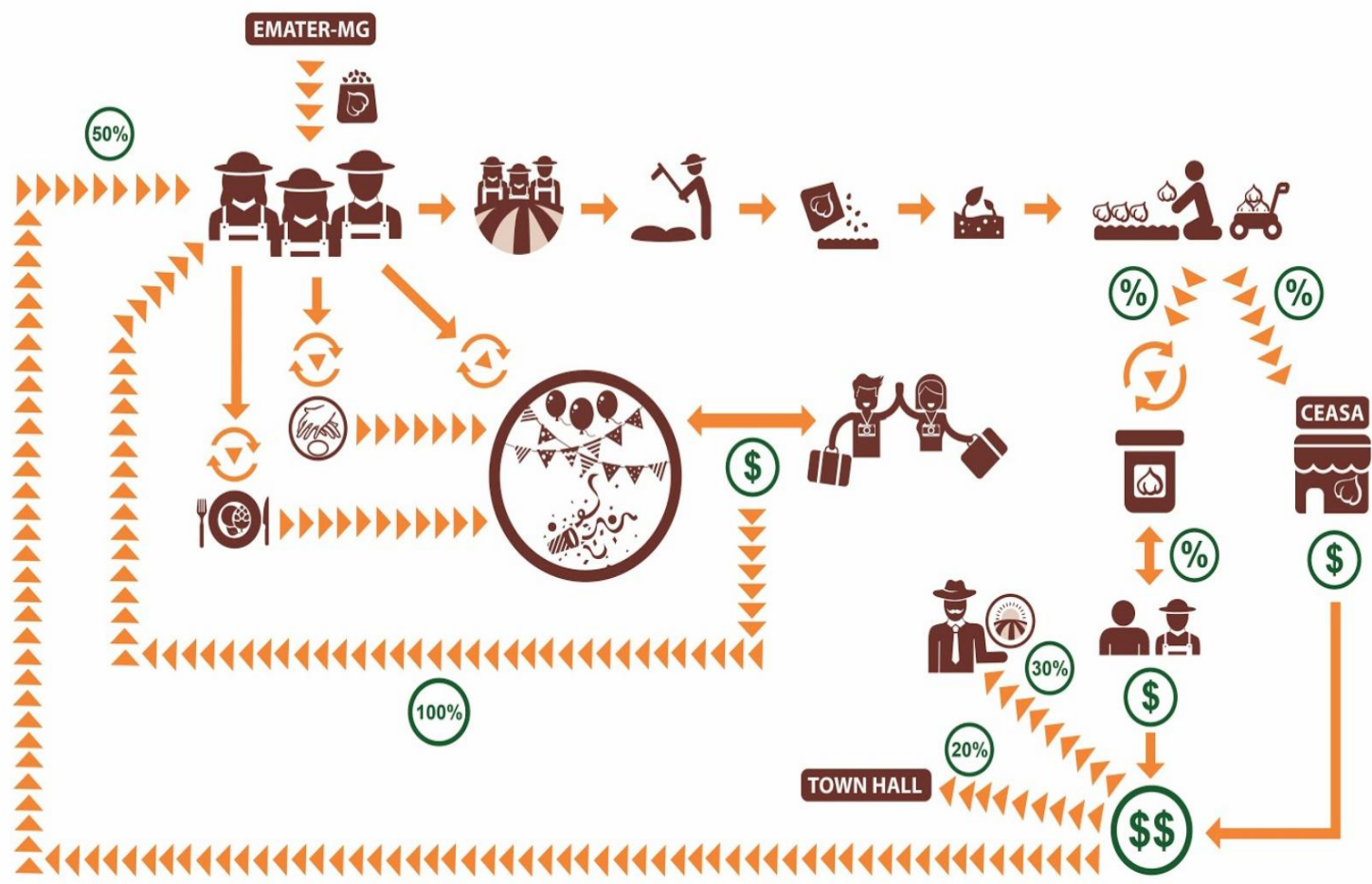

\section{LEGENDA}

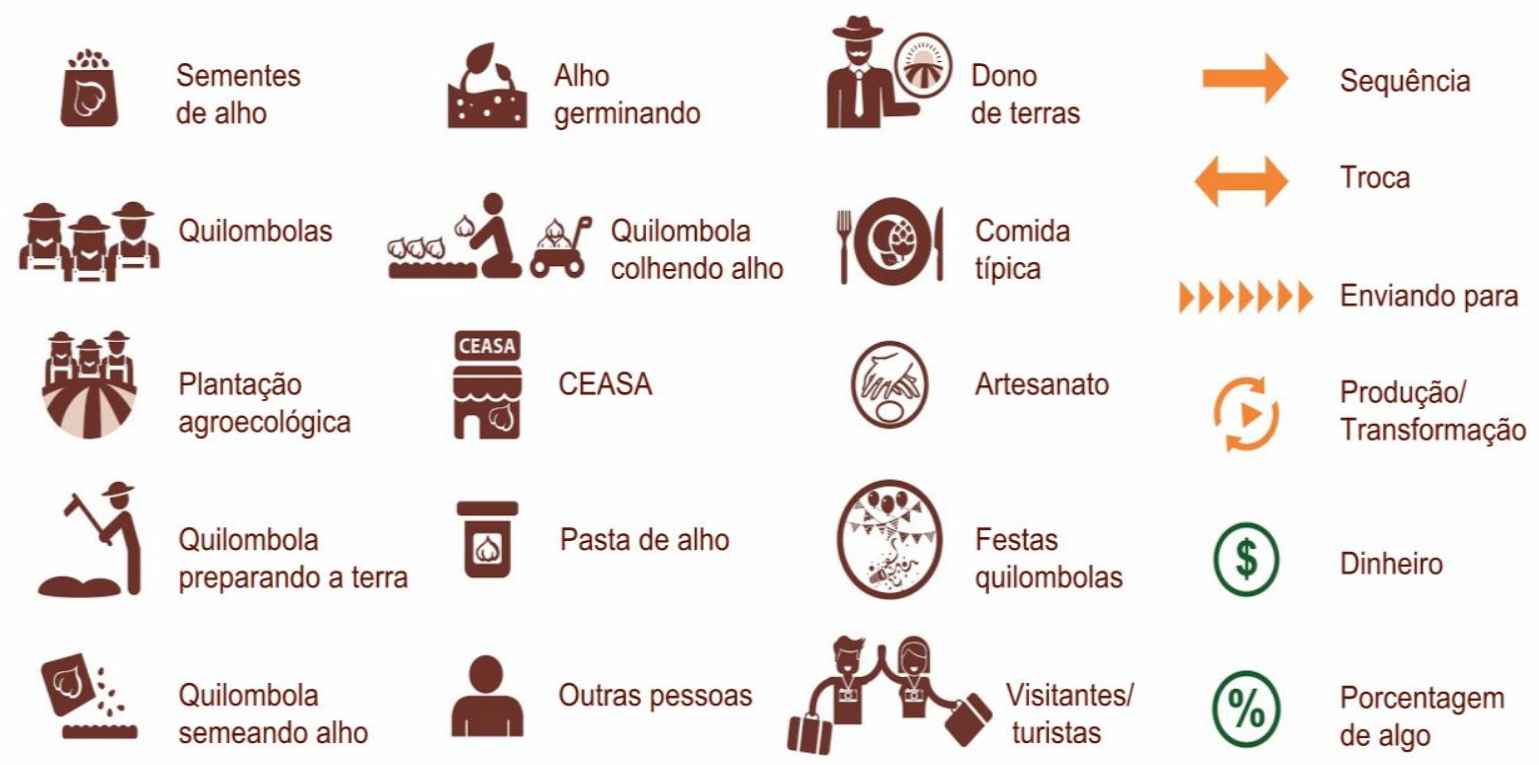

Fonte: Elaborado pela equipe do projeto (2017). 
Por meio desse mapa a equipe avaliou os pontos do sistema que poderiam ser beneficiados por um projeto de design social e de serviços. Os pontos selecionados foram:

- Criação de identidade visual para a comunidade que atenda também aos produtos comercializados por ela.

- Criação de artes para a comunicação da identidade visual da comunidade de Felipe e para a promoção de venda de seus produtos e serviços.

- Assessoria no planejamento da organização de eventos de forma a contribuir com a otimização da produção local de artesanato, quitandas e demais alimentos.

- Produtos e serviços em sistema integrado, compatível com as habilidades dos produtores e artesãos da comunidade.

- Verificação de possibilidades de redução de custos e aumento do valor dos produtos, por meio da compreensão das necessidades do cliente, otimização do processo e apropriação do capital territorial.

\subsection{Construção de Marca e Identidade Visual}

O propósito da marca é evidenciar e fortalecer a identidade de Felipe difundindo sua cultura e promovendo seu reconhecimento como uma comunidade quilombola tradicional. 0 estudo das informações coletadas e organizadas por meio das ferramentas Product Service Systems permitiu inferir que, para todas as personas envolvidas no projeto, a ideia de comunidade tradicional quilombola envolve conceitos tais como: hábitos comunitários, união, trabalho coletivo, preservação de culturas e tradições, trabalho manual artesanal, trabalho com a terra, plantio agroecológico e harmonia com a natureza.

Esses conceitos despertam emoções que fazem com que o público externo desenvolva empatia por uma comunidade com essas características, o que gera valor tanto para ela quanto para seus produtos e serviços. No caso das personas que pertencem à comunidade, essas emoções incluem afeto pela comunidade e honra indentitária. Esses fatores podem contribuir, por exemplo, para a geração ou o fortalecimento de sentimentos de união e de pertença. Nesse sentido, percebeu-se que, para alcançar seu propósito, a marca deve gerar efeitos emocionais no público e, portanto, deveria materializar tais conceitos em formas icônicas. A Figura 6 apresenta a marca desenvolvida para a comunidade quilombola de Felipe e sua aplicação em materiais gráficos projetados para sua divulgação. Tais trabalhos de design gráfico foram projetados por uma designer profissional do grupo de atuação.

Figura 6 - Marca desenvolvida para a comunidade Quilombola de Felipe aplicada em produtos gráficos.

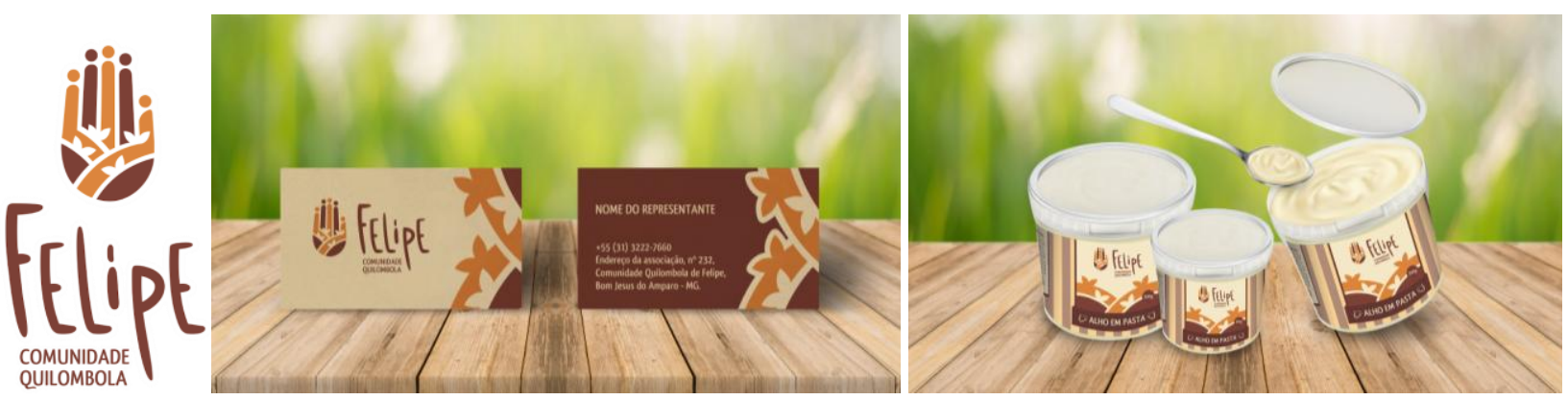

Fonte: Elaborado pela equipe do projeto (2017). 
Prevendo possíveis situações de necessidade de redução de custos na produção de material gráfico, foi sugerida a produção de carimbos com a marca, para sua aplicação versões alternativas de embalagens, tags e cartões (Figura 7). Nesse caso, o sistema de aplicação da marca não necessita de máquinas ou de profissional especializado, pois aplicação de carimbos exige pouca habilidade do aplicador.

Figura 7 - Carimbo para aplicação da marca em versões alternativas de material gráfico.

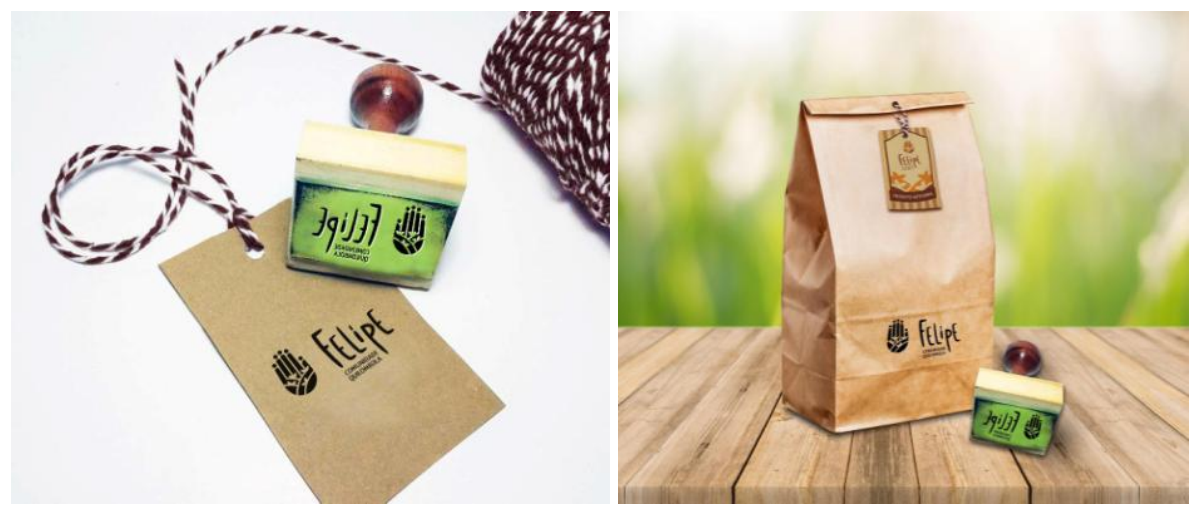

Fonte: Elaborado pela equipe do projeto (2017).

Assim, após a etapa de preparação da comunidade para adaptações do sistema de produção local, que envolve um sistema de Arranjo Produtivo Local, foi preciso realizar um novo levantamento de dados para a realização do projeto de gastronomia quilombola em PSS. Nessa nova etapa, foram detalhados os custos de produção, estabelecendo os limites e potenciais do negócio proposto: um buffet tipicamente quilombola para eventos.

\section{Projeto Sabores da Terra}

O projeto denominado "Buffet Sabores da Terra - Comunidade Quilombola de Felipe" foi desenvolvido para a comunidade com a participação de seus integrantes. Com o objetivo de desenvolver um negócio rentável explorando o potencial das ações já desenvolvidas na comunidade, propôs-se um serviço de buffet tipicamente quilombola para atender a eventos da região com o aproveitamento dos recursos locais. Com base nos conceitos PSS, foi definida a unidade de satisfação do buffet como sendo o destaque especial para a culinária tradicional afrobrasileira bem como para a produção ecologicamente correta. Para tanto, foi definido que: os colaboradores do buffet devem ser integrantes da comunidade de Felipe; o cardápio do buffet deve ser composto por receitas originais da cultura quilombola afrobrasileira ou por adaptações destas, sempre mantendo características típicas; a compra dos ingredientes usados na produção dos alimentos fornecidos deve visar a produção agroecológica local sempre que ela atender a demanda e que o Aproveitamento Integral de Alimentos (AIA) deve ser aplicado.

É frequente ainda um grande desperdício de partes dos alimentos tais como cascas e talos. Uma das iniciativas para inibir esse desperdício é o chamado Aproveitamento Integral de Alimentos (AIA) que consiste em evidenciar, através de receitas de pratos doces e salgados, a viabilidade do aproveitamento de todas as partes saudáveis dos alimentos. Esses pratos são comercializados através de eventos, estabelecimentos comerciais como restaurantes além de feiras gastronômicas, mas ainda são pouco populares (LAURINDO, 2014). 
O desperdício de alimentos é um problema mundial no âmbito da sustentabilidade. De acordo com a $\mathrm{ONU}^{2}$, aproximadamente um terço dos alimentos é desperdiçado desde a produção até o consumo. Esse desperdício causa diversos impactos negativos, como a excessiva produção de lixo, emissão de gases poluentes, desperdício de recursos financeiros e naturais além de deixar de cumprir sua função primária que é saciar a fome.

De acordo com os objetivos do desenvolvimento sustentável (ODS), Agenda $2030^{3}$, será preciso ainda, para o futuro, criar padrões de produção e consumo sustentáveis, que impliquem basicamente em adotar medidas para a utilização eficiente dos recursos naturais, minimizando as perdas e desperdícios em todo o processo desde a produção até o consumo e produção de resíduos (ONU, 2015).

Os produtos tradicionais podem ser resgatados pela educação do paladar, do conhecimento dos alimentos, do respeito à cultura e aos saberes dos antepassados, aplicando a praticidade e criatividade do design. Dessa forma, estabelecer o elo entre conceitos e a prática através da gastronomia, pode gerar possibilidades de produção ecoeficiente, preservando a identidade cultural dos quilombolas, seus processos e insumos utilizados.

Essa proposta de negócio baseada no Product Service Systems no AIA (Aproveitamento Integral de Alimentos) visa gerar emprego para os integrantes de Felipe e promover a geração interna de renda. A ênfase na cultura quilombola e sua gastronomia afro-brasileira, bem como nas formas de produção artesanal e ecologicamente corretas, é uma estratégia para agregar valor cultural e tradicional aos produtos e ao serviço do buffet, o qual agregará esses valores também aos eventos atendidos por ele. A Figura 8 mostra o registro fotográfico de um dos encontros realizados com a comunidade para esclarecer como o projeto poderia ser desenvolvido.

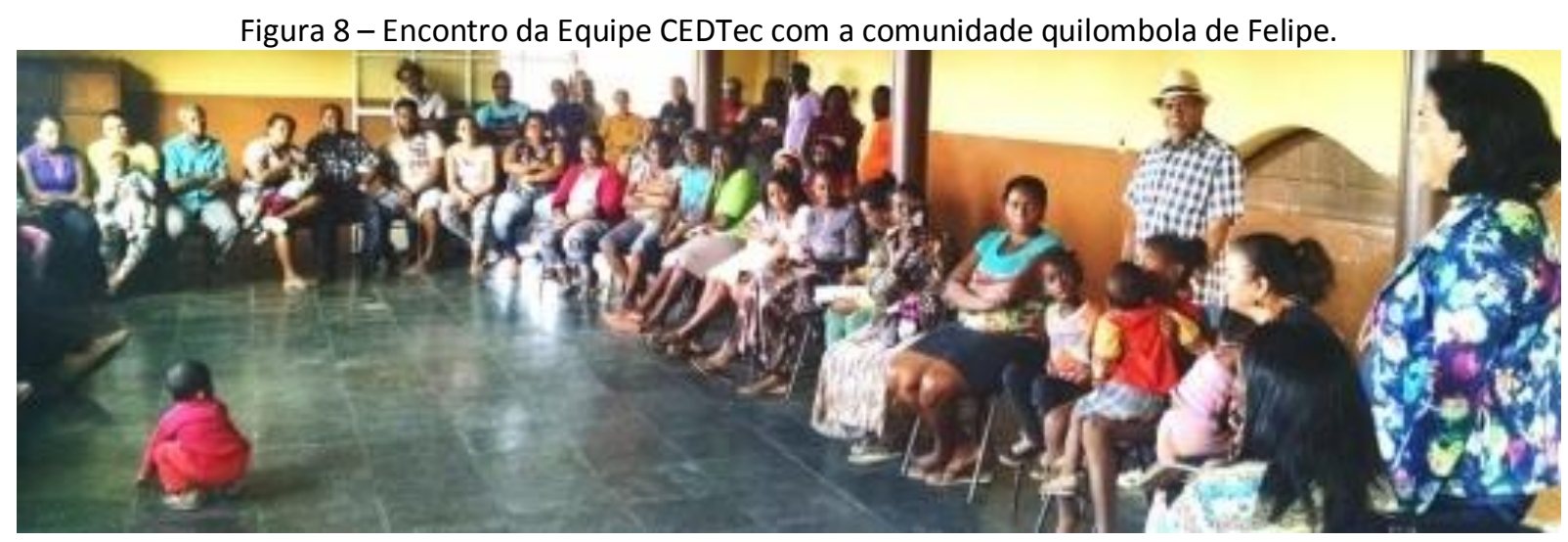

Fonte: Acervo do projeto (2017).

Para a configuração dos ambientes de realização dos eventos (ambientação dos espaços) propõe-se o uso de materiais naturais (bambus, frutos e folhagens) que são plantados e beneficiados na própria comunidade. Esses materiais são orgânicos e após os eventos são destinados à adução de alimentos cultivados para atender às demandas locais e dos eventos.

\footnotetext{
${ }^{2}$ A ONU anunciou o lançamento do primeiro padrão global para medir perda e desperdício de alimentos. Ver publicação veiculada no site da ONUBR <www.nacoesunidas.org $>$.

${ }^{3}$ A Agenda 2030 para o Desenvolvimento Sustentável, proposta em 2015 pela ONU, estabeleceu dezessete objetivos e 169 metas a serem desenvolvidas pelos países em busca da concretização dos direitos humanos.
} 
Entre os elementos de adornos destacam-se os produtos que remetem á lembrança da cultura africana: vasos, cestos, flores secas. Os adornos poderão ser reaproveitados de um evento a outro, sem gerar custos para o negócio. Os produtos artesanais expostos poderão ser comercializados. Assim, o "Buffet Sabores da Terra - Comunidade Quilombola de Felipe" propõe uma forma de atuação que também divulga a produção dos artesãos durante os eventos e difunde aspectos da cultura quilombola.

Os trajes utilizados pela equipe do buffet foram inspirados nas vestimentas típicas da cultura africana. Utiliza-se de tecidos leves e coloridos em algodão (confortáveis e biodegradáveis) sendo que a confecção de alta qualidade em acabamento pode ser realizada por mulheres da comunidade, tornando a apresentação dos garçons e garçonetes outro ponto relevante de valor agregado e visualmente característico, particular, gerando um diferencial. Os retalhos dos tecidos utilizados na produção de figurinos para os eventos poderão ser aproveitados para a criação de bonecas, bolsas e colchas de retalhos, comercializados nas feiras de artesanato organizadas pela prefeitura local, em datas comemorativas.

Essa tendência de produção de eventos temáticos especializados tem apresentado resultados satisfatórios. Conforme consta no site da Catering BatterCater, com sede na Califórnia/USA, esta inovação garante um diferencial no serviço. A BatterCater apresenta-se como uma ferramenta para agilizar, organizar e desenvolver negócios de restaurantes, em tamanhos e áreas diversas. Da elaboração do cardápio ao gerenciamento e economia de tempo a empresa atua em catering corporativo, catering para eventos, catering local, restaurantes e franquias de alimentos, preparação em alimentos em grande escala e entrega de alimentos em caminhões.

Na Figura 9, são apresentadas referências de trajes, ambientação de eventos e exposição de produtos para o "Buffet Sabores da Terra - Comunidade Quilombola de Felipe".

Figura 9 - Referências de trajes, ambientação de eventos e exposição de produtos para o buffet.

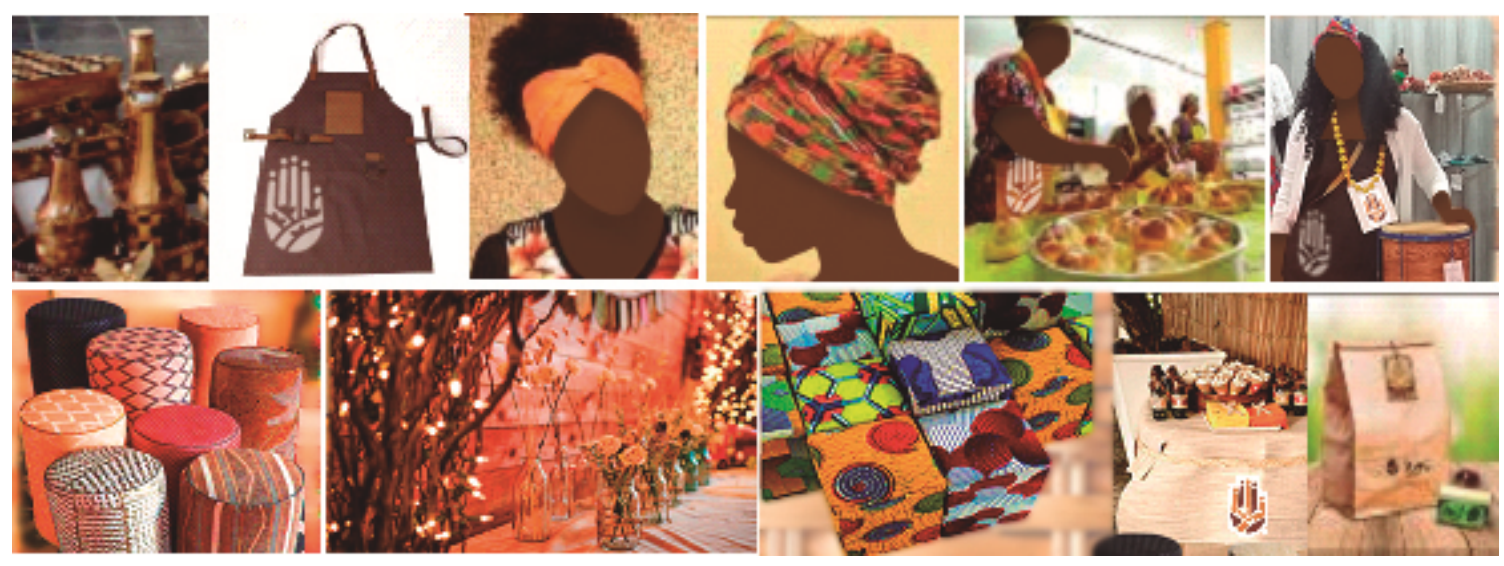

Fonte: Elaborado pela equipe do projeto (2017).

A Comunidade Quilombola de Felipe, prioritariamente, propõe recuperar e difundir receitas e quitandas com base na culinária afrobrasileira presente na memória da comunidade. Desde a contratação de pessoal (da própria comunidade e outros com experiência e que sigam o padrão de qualidade), pagamentos alternativos de produtos e gerenciamento de resíduos o "Buffet Sabores da Terra - Comunidade Quilombola de Felipe" busca pela excelência em serviços de buffet, sem perder a simplicidade e as tradições culturais da comunidade quilombola. 
O cardápio do "Buffet Sabores da Terra - Comunidade Quilombola de Felipe" foi configurado para atender eventos corporativos, empresas, prefeituras e também à comunidade em geral. Assim, há sempre um momento para estudo e refinamento das receitas dos alimentos servidos. Utiliza-se nos pratos salgados o tempero com a pasta de alho, produto desenvolvido pela associação de produtores rurais da comunidade quilombola. As doceiras e quitandeiras da comunidade também oferecem produtos doces para serem servidos nos eventos. $O$ ciclo de utilização de alimentos plantados, coletados e produzidos por pessoas da própria comunidade fortalece ao desenvolvimento local. Os agricultores da região recebem do evento os resíduos que possam ser utilizados na permacultura.

O SPS tem o potencial de minimizar os impactos ambientais da produção e do consumo. Nesse sentido, entre os produtos alimentícios do cardápio para os eventos, destaca-se o Pastel de Angu - iguaria da cultura afrobrasileira. Além de agregar o tempero de alho (produção local) utiliza o milho dos produtores rurais locais, apreciado em todas as festas da região. $O$ pastel de milho da tradição quilombola é servido em embalagem confeccionada com a casca do milho. Outros produtos são elaborados pelo sistema de Aproveitamento Total de Alimentos, com a utilização da casca de frutas e legumes no preparo (Figura 10). Propõe-se um trabalho com produtos orgânicos da produção comunitária e mão de obra local treinada para atender aos eventos, de acordo com Costa (2013).

Figura 10 - Exemplos de pratos oferecidos pelo "Buffet Sabores da Terra - Comunidade Quilombola de Felipe".

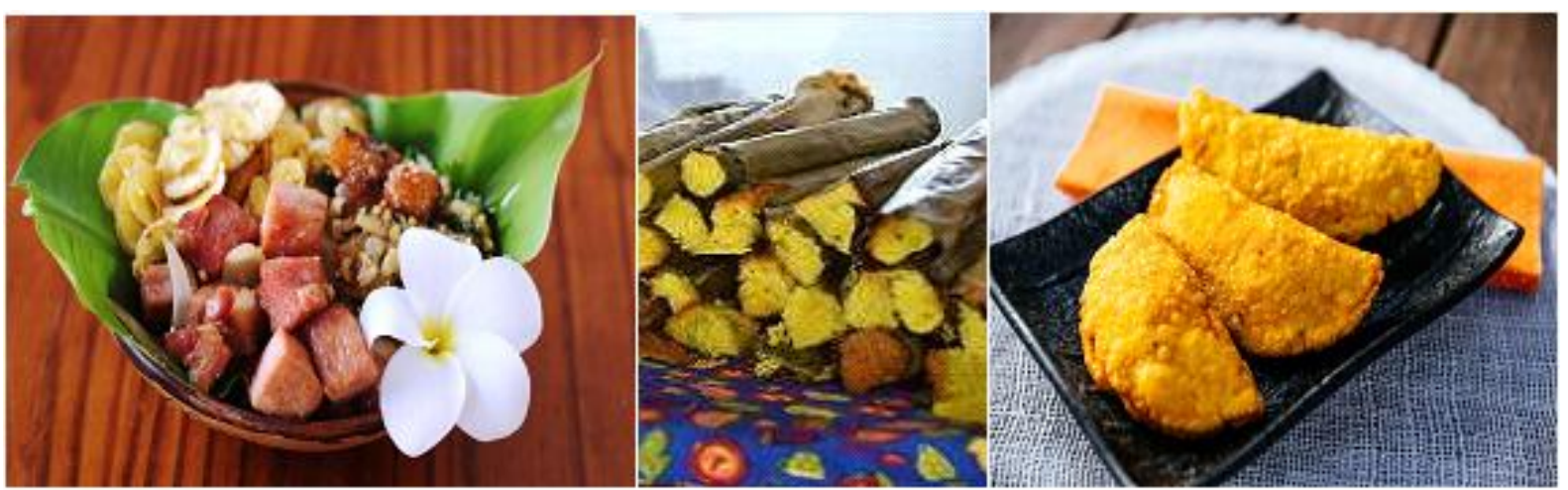

Fonte: destemperados.com.br (2017).

A culinária quilombola sempre foi um dos destaques na cultura afrobrasileira. Pratos simples, ingredientes locais. O Resgate de receitas caseiras e afetivas é um modo de eternizar e difundir receitas centenárias e atender um público diferenciado de forma singular e atrativa. $\mathrm{O}$ planejamento e programação visual geral é um agregado de grande relevância que conta com a atuação do design desde o planejamento e a logística de produção, até a embalagem, apresentação e comunicação.

A proposta é oferecer ambientes caracterizados, imbuídos de tradição e cultura para mostrar e valorizar traços identitários e diferenciais do serviço. Muito mais que personagens caricaturalmente expostos a serviço do lucro, trata-se de um negócio em modelo sistêmico que reduz matéria prima, recursos e mão de obra, pois toda a equipe é treinada para atender os objetivos da proposta. Neste projeto, o design encontra-se em um papel ampliado de sua função na sociedade atual que vai muito além do produto-empresa-mercado. Na complementação do sistema foi gerado, ainda, um plano estratégico que envolve a divulgação do buffet em redes 
sociais, sites de apoio a projetos sociais e outros meios virtuais e não virtuais de comunicação.

Para dar mais solidez à apresentação do negócio para clientes e parceiros, a equipe do projeto elaborou um pitch sobre os serviços do "Buffet Sabores da Terra - Comunidade Quilombola de Felipe".

Pitch é uma técnica de apresentação rápida de uma ideia ou oportunidade de negócio com o objetivo de captar investidores, que pode durar de 30 segundos a 20 minutos. É praticada em vários suportes, como: pessoalmente, vídeo, em conjunto (equipe), entre outros. A equipe optou por um pitch de 90 segundos que inicia com a apresentação do grupo de quilombolas da comunidade de Felipe, o que eles pretendem oferecer como produto e serviço aos clientes e parceiros e quais são as vantagens de investimentos nessa proposta.

\section{Resultados e Considerações}

A equipe de designers e pesquisadores do CEDTec buscou atender ao pedido da Secretaria Executiva do Território Metropolitano/Fóruns Regionais, realizando a adaptação das atividades de gerenciamento de produtos na comunidade quilombola de Felipe e executando sua estruturação em beneficiamento dos recursos em Arranjo Produtivo Local.

Em todas as etapas de desenvolvimento do projeto foi pensado como poderiam integrar as atividades com a participação da comunidade, estabelecendo o que seria para eles a unidade de satisfação. Assim, oferecer serviços de buffet para eventos na região com o máximo aproveitamento dos recursos locais é uma meta que pode se consolidar por meio da aplicação do PSS.

A unidade de satisfação, isto é, aquilo que se deseja oferecer, é a culinária afrobrasileira, presente na memória quilombola da comunidade de Felipe, com base no Aproveitamento Integral de Alimentos, agregando ao projeto, como diferencial, o valor da cultura afrodescendente, bem como da produção artesanal e sustentável. Este significativo esforço deve dedicar ações que impulsionem e realimentem esse processo de integração entre produtos e serviços para gerar uma vantagem competitiva sustentável.

Foram delineados quatro modelos de atuação do PSS:

- Serviços de resultados - Desenvolvimento de um negócio local utilizando as habilidades da comunidade, desenhando a redução significativa de recursos utilizados em modelos convencionais de buffet;

- Serviços de utilização compartilhada de bens e produtos - Práticas de produção de alimentos em atividades compartilhadas de forma a gerar uma um fluxo de economia distribuída;

- Serviços de extensão de vida útil de produtos - Sistema de reutilização de materiais e ciclo de vida do produto, aplicando o Aproveitamento Integral de Alimentos e a Permacultura;

- Gerenciamento de demanda compartilhada e distribuída de bens e produtos - Fomento e estratégica na montagem dos eventos com cenários temáticos, trajes inspirados na cultura banta, exposição de produtos da comunidade e atuação efetiva em redes sociais, sites e meios de comunicação.

O trabalho buscou demonstrar que o "Buffet Sabores da Terra: Comunidade Quilombola de 
Felipe" não visa apenas a comercialização de produtos por si mesmos, mas todo um território que os contextualiza. Altera o foco de um produto físico para um serviço que possa satisfazer as necessidades do cliente e demais demandas, atendendo com recursos reduzidos. Ao mesmo tempo, difunde a cultura quilombola como um produto, como um valor.

O mix produto/serviço foi aplicado para analisar e detalhar o sistema de produção e comercialização de cada área: no plantio, na coleta, na elaboração de alimentos para o buffet, na elaboração de produtos artesanais, no sistema de comercialização dos produtos da comunidade, na organização dos eventos, na participação das famílias nesses eventos - economia popular, na destinação dos resíduos, no acompanhamento dos resíduos como fertilizante para a lavoura local. Assim, o diferencial de PSS se apresenta no ciclo exibido, que é um motivador para a comunidade desenvolver outros sistemas de produtos e serviços que possam ser agregados ao modelo piloto.

\section{Referências}

BATTERCATER. Best Cater makes your life easier, guaranteed.

(https://www.bettercater.com/\#benefit-area).

COOK, M. Understand the potential offered by service-oriented concepts to improve resource productivity. In: Bhamra, Tracy and Hon, Bernard eds. Design and Manufacturing for Sustainable Development. Bury St. Edmonds, UK: Professional Engineering Publishing Limited, 2004.

COSTA A. F.; PRENDEVILLEB, S.; BEVERLEYA, K.; TESOC, G; BROOKER, C. Sustainable productservice systems for an office furniture manufacturer: How insights from a pilot study can inform PSS design, 2013.

DESTEMPERADOS. (www.destemperados.com.br)

FINKEN, K. H.; MCALOONE, T. C.; AVLONITIS, V.; GARCIA I MATEU, A.; ANDERSEN, J. A. B.; MOUGAARD, K.; HSUAN, J. PSS Tool Book: A workbook in the PROTEUS series. Technical University of Denmark/DTU. PROTEUS Workbook series; No. PRO-04, 2013.

HALEN, C. V.; VEZZOLI, C.; WIMMER, R. Methodology for Product Services System Innovation. Assen: Uitgeverij Van Gorcum, 2005. p. 21.

LAURINDO, T. R.; RIBEIRO, K. A. R. Integral use of food in Interciencia and Sociedade. V3, n.2. Mogi Guaçu: Faculty Municipal Professor Franco Montoro, 2014.

(http://fmpfm.edu.br/intercienciaesociedade/colecao/online/v3_n2/vol3_n2_online.pdf)

MANZINI, E. Design for social innovation and sustainability: creative communities, collaborative organizations and new project networks. Translation of C. Cipolla. Rio de Janeiro: E-papers, 2008.

ONU/ ONUBR - NACOESUNIDAS.ORG . Transforming Our World: The 2030 Agenda for Sustainable Development. Translation United Nations Information Center for Brazil. UNIC Rio, 2015. (https://nacoesunidas.org/pos2015/agenda2030/)

PREFEITURA DE BOM JESUS DO AMPARO. (http://www.bomjesusdoamparo.mg.gov.br/) ROY, R. Sustainable Product-Service Systems. Futuros, vol. 32, no.3-4, 2000. p.289-299. 


\section{Artigo Completo}

\section{Agradecimentos}

Professora da Disciplina de Doutorado PSS (PPGD/EUMG) - Rita de Castro Engler, PhD.

Prefeitura da Cidade de Bom Jesus do Amparo/Minas Gerais

Associação da Comunidade Quilombola de Felipe - Cidade de Bom Jesus do Amparo/MG

Fóruns de Desenvolvimento Regional de Minas Gerais - Governo de Minas Gerais 